Kong. Res. J. 1(1) : 90-94, 2014

Kongunadu Arts and Science College, Coimbatore

\title{
STUDY ON THE PLANT SPECIES, ACORUS CALAMUS FOR INSECTICIDAL PROPERTIES AGAINST THE FILARIAL VECTOR, CULEX QUINQUEFASCIATUS SAY. (DIPTERA: CULICIDAE).
}

\author{
Rajmohan D.* and K. Logankumar \\ Department of Zoology, Kongunadu Arts and Science, College, Coimbatore. \\ *E.mail : rajmohandevadass@gmail.com
}

\begin{abstract}
Leaf extract of the species, Acorus calamus was evaluated for the egg hatchability, larvicidal and pupicidal activity and the protein content of mosquito, Culex quinquefasciatus under the room temperature in the laboratory. Dosage value as expressed in ppm was 10 to 140 for Culex quinquefasciatus. A relationship was observed between the plant extract doses and percentage mortality. The percentage of egg hatchability decreased; larval and pupal mortality were found to be increased with increase in the dosage. Based on the probit analysis, the $\mathrm{LC}_{50}$ value of egg (99.15), I instar (42.24), IV instar (101.49) and pupae $(121.57 \mathrm{mg} / \mathrm{mL})$ were recorded. The ovary protein content of the treated $(0.083)$ was estimated to be very low when compared with that of the control $(0.172 \mathrm{mg} / \mathrm{mL})$.
\end{abstract}

Keywords: Culex quinquefasciatus, Acorus calamus, $\mathrm{LC}_{50}$, protein.

\section{INTRODUCTION}

Vector control is a serious concern in developing countries like India due to lack of general awareness, development of resistance and socioeconomic reason. The role of mosquitoes is becoming increasingly important in the recent years because of change in ecology caused by human intervention.

Mosquitoes constitute a major public health menace as vectors of serious human diseases (Logankumar et al., 2008). Of the various mosquito spread diseases, filariasis transmitted by Culex quinquefasciatus is dangerous and is spreading into wucherria bancrofti have taken epidemic form and have been reported from Tamil Nadu, West Bengal, Uttar Pradesh, Gujarat and Delhi (Kebra et al., 1992). In recent years, scientists try a variety of botanical derivatives to eradicate many harmful insect pests including mosquitoes. Insecticidal activity of neem has been reported. Vector control is facing a threat due to the emergence of resistance to synthetic insecticides. Insecticides of botanical origin may serve as suitable alternative biocontrol techniques in the future (Nandita Chowdhury et al., 2008).

Aedes are vectors for the pathogens of various diseases like dengue fever, dengue haemorrhagic fever and yellow fever (Rajmohan and Ramaswamy, 2007). Many authors world wide started large screening activity for using extracts of medicinal and herbaceous plants to control mosquitoes (Halawa, 2001; Das et al., 2003; Choochote et al., 2004). The plant species, Acorus calamus is a widely distributed neotropical shrub introduced to many parts of the tropics.

For the present study, this species was screened against egg hatchability, larval and pupal mortality of the mosquito Culex quinquefasciatus. So as to control the population of Culex quinquefasciatus by an eco-friendly approach.

\section{MATERIALS AND METHODS}

Fresh leaves of Acorus calamus were collected from the plants growing in agricultural lands. Leaves were washed, shade dried and ground in a mixture to form a fine powder. The $25 \mathrm{~g}$ of the powder was then used for extraction in acetone in soxhlet apparatus. The extract was concentrated on water bath to evaporate the acetone. The filterate was considered as pure material and redissolved in acetone to form standard formulation. By further dilutions with required amount of water, different doses (ppm) were prepared.

Eggs of Culex quinquefasciatus were procured from the Research Laboratory of National Institute of Communicable Diseases (NICD), Mettupalayam, Coimbatore and brought to the laboratory and cultured. Eggs, first and fourth larval instars and pupae were harvested from the colony and were placed in different concentrations as biocide. Twenty individuals were used for each concentration. Eggs, larval instars and pupae were checked for mortality for every 24 hours. In the case of control only, carrier solvent was added. Food was provided in all the test beakers. Each test was 
replicated for five times.The effect of leaf Acorus calamus on the egg hatchability, mortality of first and fourth larval instars and pupal mortality of Culex quinquefasciatus was studied. Following 24 hours were corrected for natural response by Abbott's formula (Abbott, 1925) as follows:

Busvin (1971) suggested that the critical doses of susceptibility can be estimated with sufficient accuracy from a probit / log concentration graph. Based on the log concentration and the probit mortality percentage values, regression equation was obtained. Using the regression, a straight line was fitted. Fitting of regression line and homogeneity of population were also tested employing chi-square $\left(\chi^{2}\right)$ test. By graphical interpolation, $\mathrm{LC}_{50}$ values of the leaf extract for 24 hours of exposure of egg, first and fourth instar larvae and pupae of Culex quinquefasciatus and their fiducial limits (95\% upper fiducial limit and lower fiducial limit) were calculated.

Blood fed females survived through pupae treated with any concentration of plant extract was harvested at different hours. The ovaries were carefully dissected out and washed in physiological saline solution. The adhering water the tissues were removed using filter paper. The ovaries were weighed and homogenized in phosphate buffer $(\mathrm{pH}$ $7.0 ; 0.01 \mathrm{M}$ ). The sample was then centrifuged at $5000 \mathrm{rpm}$ for 10 minutes and supernatant was taken for the estimation of protein by adopting standard methods for protein determination.

\section{RESULTS AND DISCUSSION}

Mortality values of egg, larvae and pupae treated with different concentrations (ranging from $10 \mathrm{ppm}$ to $140 \mathrm{ppm}$ ) of the leaf extract of Acorus calamus at the end of $24 \mathrm{hrs}$ are given in Table 1-4 for egg, I instar, IV instar larvae and pupae of Culex quinquefasciatus. The $\mathrm{LC}_{50}$ values and their 95\% upper and lower fiducial limits, and chi-square value of the leaf extract of Acorus calamus for $24 \mathrm{~h}$ exposure of Culex quinquefasciatus are given in Table 5 . Based on the probit analysis the $24 \mathrm{hr} \mathrm{LC}_{50}$ value of the leaf extract of Acorus calamus for egg, I instar and IV instar larvae and pupae of Culex quinquefasciatus was found to be 99.15, 42.24, 101.49 and 121.57 respectively (Fig.1). The ovary protein content of the treated was estimated to be very low when compared with that of the control (Table 6). An important criterion determine in the present study the enzyme activity declined invariably in all the treatments of Culex quinquefasciatus with Acorus calamus leaf extract. Decline in the ovary protein content will reduce the egg laying capacity of Culex quinquefasciatus where as inhibition of enzyme activity will help in the arresting of the developmental stages. Inhibitory effect of Acorus calamus leaf extract was found to be higher than that of the synthetic inhibitors. The visible morphological abnormalities occurred in treated were the larva were smaller than that of its control. Pupae survived through larval treatment frequently showed a variety of malformations like demelanized pupa with straight abdomen, partially melanised pupa with extended abdomen, dwarf pupa with retarded abdomaen, dechitinised pupa and inability of the adult to shed completely its exiuuvia which remained attached to its appendages. These results are in agreeing with the earlier findings made by many workers with botanicals for various properties (for oviposition avoidance, Tilak et al., 2005; larvicidal, Halawa, 2001; Khater, 2003; Saleh, 1995, adulticidal, Choochote et al., 2004 and repellent activities, Choochote et al., 2004; Prakash et al., 2000). As the botanical insecticides for including the extract of $C$. odarata are biodegradable and harmless to the environment, pest - specific and relatively harmless to non-target organisms ( $\mathrm{Su}$ and Mulla 1998; Sivagnaname and Kalyana Sundaram, 2004; Sun et al., 2006) they are more eco-friendly. The three active principle compounds reported in the study species Acorus calamus such as Augustineolide, $3-\beta-6$ hydroxy, dihydroxy cartin and 6 - acetoxihumininolide are determined to have mosquitosidal properties which is perhaps be a reason for the medicinal use of this species in terms of mosquito repellent (Logankumar, 2006). The results of the present study, indicate that the leaf extract of the species, Acorus calamus caused low percentage of egg hatchability and high percentage of larval and pupal mortality. Hence the large biomass of Acorus calamus available in Southern India can be used in the pharmacological industries to obtain effective repellent to control mosquito population is an ecofriendly manner.

\section{REFERENCES}

Abbott, W.S. (1925). A method for computing effectiveness of an insecticide. J. Econ. Entomol., 18: 265-267.

Busvin, R.J. (1971). A critical review of the technique for testing unsecticides. Common Wealth Agricultural Bureau, London, 263 - 288.

Cheng, S.S., H.T. Chang, S.T. Chang, K.H. Tsai, and W.J. Chen, (2003). Bio activity of selected plant essential oils against the Yellow fever mosquito, Culex quinquefasciatus larvae. Biores. Technol., 89(1): 99 - 102. 
Choochote, W. Tuetun, B. Kanjana and D. Pothi. (2004). Potential of curd seed extract of celery, Apium graveolens L., against the mosquito Culex quinquefasciatus (L.) (Diptera : culicidae) J. Vector Ecol., 29: 340-346.

Nandita Chowdhury, Anupam Ghosh and Goutam Chandra (2008). Mosquito larvicidal activities of Solanum villosum berry extract against the dengue vector Stegomyia aegypti. BMC Complementary and Alternative Medicine.P. 8:10 doi:10.1186/1472-6882-8-10.

Das, N.G., I. Baruah, P.K. Talukdar and S.C. Das, (2003). Evaluation of botanicals as represents against mosquitoes. J. Vector Borne Dis, 40: 4953.

El Hag, E.A., A.H. Nadi and A.A. Zaitoon, (1999). Toxic and growth retarding effects of there plant extracts on Culex pipiens larvae (Diptera; Culicidae). Phytother. Res. 13: 388-392.

Halawa, S.M. (2001). Studies on the use of some plant extracts as factor in pest management. (Ph.D. Thesis - faculty of Agriculture, Moshtohor. Zagazig University, Benha Branch).

Isman, M.B. (1999). Pesticides based on plant essential oils. Pesticide outlook, 68-72.

Kebra, S.K., I.C. Verma, N.K. Arora, Y. Jain and V. Kalra, (1992). Dengue Haemorrhagic fever in children in Delhi. Bull. WHO, 70(1): 105-108.

Logankumar, K., D.S. Rajmohan and Logaswamy, (2008). Evaluation of seed extract of Pongamia pinnata against the growth and development of the mosquito Culex Quinquefasciatus. Indian J. Environ. And Ecoplan. 15(1-2) : 303 - 308.

Logankumar, K. (2006). Final technical report (UGC minor research project) Studies on the efficacy of a botanical insecticide Swetenia macrophylla (Meliaceae) on the growth and development of the domestic mosquito, Culex quinquafasciatus Say (Diptera: Culicidae).

Prakash, A., D.R. Bhattacharya, P.K. Mophapatra and J. Mahanta, (2000). Preliminary field evolution of repellent action of neem oil in Assam against two mosquito vectors of Japanese encephalitis. J. Paras. Dis., 24: 221 - 222.

Rajmohan, D. and M. Ramaswamy, (2007). Evalution of larvicidal activity of the leaf extract of a weed plant, Ageratina adenophora, against two important species of mosquitoes, Culex Quinquefasciatus and Culex quinquefasciatus. African J. of Biotecnology Vol. 6(5): 631-638.

Saleh, E.H. (1995). Effect of some botanical extracts as potential insecticides for the control of some mosquitoes in Egypt, 1995. (Ph.D., Dept. Entomol. Fac. Sci. Cairo. Univ., Egypt.)

Sivagnaname, N. and M. Kalyanasundaram, (2004). Laboratories evaluation of methanolic extract of Atlantia monophylla (Family: Rutaceae) against immature stages of mosquitoes and non-target organisms. Mem. Inst. Oswaldo Cruz, 99: 115 - 118 .

$\mathrm{Su}$, T. and M.S. Mulla, (1998). Ovicidal activity of neem products (Azadirachtin) against Culex tarsalis and Culex quinquefasciatus (Diptera: Culicidae) J. Amer. Mosq. Contrl. Ass., 14: 204 209.

Sun, L., H. Dong and C. Guo, (2006). Larvicidal activity of extracts of Ginkgo biloba exocarp for three different strains of Culex pipiens pallens. J. Med. Entomol., 43: 258 - 261.

Table 1. Effect of partially purified sample of Acorus calamus against the egg hatchability of Culex quinquefasciatus.

\begin{tabular}{|c|c|c|c|c|c|c|c|c|c|c|}
\hline \multirow{3}{*}{$\begin{array}{c}\text { No of eggs } \\
\text { exposed }\end{array}$} & \multicolumn{10}{|c|}{ Concentration (ppm) } \\
\hline & \multicolumn{2}{|c|}{70} & \multicolumn{2}{|c|}{80} & \multicolumn{2}{|c|}{90} & \multicolumn{2}{|c|}{100} & \multicolumn{2}{|c|}{110} \\
\hline & $\mathrm{h}$ & uh & $\mathrm{h}$ & uh & $\mathrm{h}$ & uh & $\mathrm{h}$ & uh & $\mathrm{h}$ & uh \\
\hline 20 & 17 & 3 & 14 & 6 & 11 & 9 & 6 & 14 & 3 & 17 \\
\hline 20 & 16 & 4 & 12 & 8 & 10 & 10 & 7 & 13 & 2 & 18 \\
\hline 20 & 17 & 3 & 11 & 9 & 10 & 10 & 5 & 15 & 3 & 17 \\
\hline 20 & 18 & 2 & 13 & 7 & 11 & 9 & 4 & 16 & 1 & 19 \\
\hline 20 & 15 & 5 & 11 & 9 & 10 & 10 & 5 & 15 & 4 & 16 \\
\hline Mean & 16.6 & 3.4 & 12.2 & 7.8 & 10.4 & 9.6 & 5.4 & 14.6 & 2.6 & 17.4 \\
\hline SD & 1.14 & 1.14 & 1.30 & 1.30 & 0.55 & 0.55 & 1.14 & 1.14 & 1.14 & 1.14 \\
\hline Mean \% & 83 & 17 & 61 & 39 & 52 & 48 & 27 & 73 & 13 & 87 \\
\hline
\end{tabular}

h - hatched, un - unhatched 
Table 2. Effect of partially purified sample of Acorus calamus against the I Instar larvae of Culex quinquefasciatus.

\begin{tabular}{|c|c|c|c|c|c|c|c|c|c|c|}
\hline \multirow{3}{*}{$\begin{array}{c}\text { No of larvae } \\
\text { exposed }\end{array}$} & \multicolumn{10}{|c|}{ Concentrction (ppm) } \\
\hline & \multicolumn{2}{|c|}{10} & \multicolumn{2}{|c|}{20} & \multicolumn{2}{|c|}{30} & \multicolumn{2}{|c|}{40} & \multicolumn{2}{|c|}{50} \\
\hline & Alive & dead & Alive & dead & Alive & dead & Alive & dead & Alive & dead \\
\hline 20 & 19 & 1 & 17 & 3 & 12 & 8 & 11 & 9 & 2 & 18 \\
\hline 20 & 18 & 2 & 15 & 5 & 11 & 9 & 10 & 10 & 4 & 16 \\
\hline 20 & 19 & 1 & 16 & 4 & 12 & 8 & 10 & 10 & 3 & 17 \\
\hline 20 & 16 & 4 & 17 & 3 & 13 & 7 & 12 & 8 & 4 & 16 \\
\hline 20 & 17 & 3 & 15 & 5 & 11 & 9 & 10 & 10 & 5 & 15 \\
\hline Mean & 17.8 & 2.2 & 16 & 4 & 11.8 & 8.2 & 10.6 & 9.4 & 6.4 & 13.6 \\
\hline SD & 1.30 & 1.30 & 1.00 & 1.00 & 0.84 & 0.84 & 0.89 & 0.89 & 1.14 & 1.14 \\
\hline Mean \% & 89 & 11 & 80 & 20 & 59 & 41 & 53 & 47 & 32 & 68 \\
\hline
\end{tabular}

Table 3. Effect of partially purified sample of Acorus calamus against the IV instar larvae of Culex quinquefasciatus.

\begin{tabular}{|c|c|c|c|c|c|c|c|c|c|c|}
\hline \multirow{3}{*}{$\begin{array}{c}\text { No of } \\
\text { larvae } \\
\text { exposed }\end{array}$} & \multicolumn{10}{|c|}{ Concentration (pp $\underline{n})$} \\
\hline & \multicolumn{2}{|c|}{80} & \multicolumn{2}{|c|}{90} & \multicolumn{2}{|c|}{100} & \multicolumn{2}{|c|}{110} & \multicolumn{2}{|c|}{120} \\
\hline & Alive & dead & Alive & dead & Alive & dead & Alive & dead & Alive & dead \\
\hline 20 & 19 & 1 & 15 & 5 & 11 & 9 & 8 & 12 & 3 & 17 \\
\hline 20 & 18 & 2 & 12 & 8 & 10 & 10 & 9 & 11 & 2 & 18 \\
\hline 20 & 16 & 4 & 11 & 9 & 10 & 10 & 8 & 12 & 1 & 19 \\
\hline 20 & 19 & 1 & 13 & 7 & 11 & 9 & 7 & 13 & 2 & 18 \\
\hline 20 & 17 & 3 & 12 & 8 & 12 & 8 & 6 & 14 & 4 & 16 \\
\hline Mean & 17.8 & 2.2 & 12.6 & 7.4 & 10.8 & 9.2 & 7.6 & 2.4 & 2.4 & 17.6 \\
\hline SD & 1.30 & 1.30 & 1.52 & 1.52 & 0.84 & 0.84 & 1.14 & 1.14 & 1.14 & 1.14 \\
\hline Mean \% & 89 & 11 & 63 & 37 & 54 & 46 & 38 & 62 & 12 & 88 \\
\hline
\end{tabular}

Table 4. Effect of partially purified sample of Acorus calamus against the pupae of Culex quinquefasciatus.

\begin{tabular}{|c|c|c|c|c|c|c|c|c|c|c|}
\hline \multirow{3}{*}{$\begin{array}{c}\text { No of } \\
\text { larvae } \\
\text { exposed }\end{array}$} & \multicolumn{10}{|c|}{ Concentration (ppm) } \\
\hline & \multicolumn{2}{|c|}{100} & \multicolumn{2}{|c|}{110} & \multicolumn{2}{|c|}{120} & \multicolumn{2}{|c|}{130} & \multicolumn{2}{|c|}{140} \\
\hline & Alive & dead & Alive & dead & Alive & dead & Alive & dead & Alive & dead \\
\hline 20 & 18 & 2 & 15 & 5 & 12 & 8 & 9 & 11 & 5 & 15 \\
\hline 20 & 19 & 1 & 14 & 3 & 10 & 10 & 8 & 12 & 3 & 17 \\
\hline 20 & 18 & 2 & 11 & 9 & 10 & 10 & 9 & 11 & 2 & 18 \\
\hline 20 & 17 & 3 & 12 & 8 & 10 & 10 & 6 & 14 & 3 & 17 \\
\hline 20 & 16 & 4 & 11 & 9 & 11 & 9 & 7 & 13 & 4 & 16 \\
\hline Mean & 17.6 & 2.4 & 12.6 & 6.8 & 10.6 & 9.4 & 7.8 & 12.2 & 3.4 & 16.6 \\
\hline SD & 1.14 & 1.14 & 1.82 & 2.68 & 0.89 & 0.89 & 1.30 & 1.30 & 1.14 & 1.14 \\
\hline Mean \% & 88 & 12 & 63 & 34 & 53 & 47 & 39 & 61 & 17 & 83 \\
\hline
\end{tabular}


Table 5. 24 hours $\mathrm{LC}_{50}$ values (ppm) and their $95 \%$ Fiducial (upper and lower) regression equation and Chi-square $\left(\chi^{2}\right)$ values of the partially purified extract of Acorus calamus for the different developmental stages of Culex quinquefasciatus.

\begin{tabular}{|c|c|c|c|c|c|c|c|}
\hline \multirow{2}{*}{ Stages } & \multirow{2}{*}{$\begin{array}{c}\mathrm{LC}_{50} \\
(\mathrm{ppm})\end{array}$} & \multirow[t]{2}{*}{-} & \multicolumn{2}{|c|}{ 95\% Fiducial limit (ppm) } & \multirow{2}{*}{$\chi^{2}$} & \multirow{2}{*}{$X$} & \multirow[t]{2}{*}{ SE } \\
\hline & & & Upper & Lower & & & \\
\hline Egg & 99.15 & & 103.74 & 95.65 & 2.57 & 52.8 & 3.88 \\
\hline I instar & 42.24 & & 45.58 & 39.75 & 6.66 & 30.2 & 11.52 \\
\hline IV instar & 101.49 & & 105.38 & 107.61 & 4.58 & 48.8 & 5.25 \\
\hline Pupa & 121.57 & & 125.43 & 117.14 & 4.25 & 47.4 & 3.11 \\
\hline
\end{tabular}

Table 6. Determination of ovary protean during different hours of blood meal on control and treatment with Acorus calamus leaf extract in Culex quinquefasciatus.

\begin{tabular}{|c|c|c|c|c|c|c|c|c|c|c|c|}
\hline \multicolumn{12}{|c|}{ Different hours after blood meal $(\mathrm{mg} / \mathrm{mL})$} \\
\hline \multicolumn{2}{|c|}{5} & \multicolumn{2}{|c|}{10} & \multicolumn{2}{|c|}{15} & \multicolumn{2}{|c|}{20} & \multicolumn{2}{|c|}{25} & \multicolumn{2}{|c|}{30} \\
\hline $\mathrm{C}$ & $\mathrm{T}$ & $\mathrm{C}$ & $\mathrm{T}$ & $\mathrm{C}$ & $\mathrm{T}$ & $\bar{C}$ & $\mathrm{~T}$ & $\bar{C}$ & $\mathrm{~T}$ & $\mathrm{C}$ & $\mathrm{T}$ \\
\hline 0.154 & 0.083 & 0.188 & 0.121 & 0.197 & 0.131 & 0.200 & 0.142 & 0.241 & 0.151 & 0.168 & 0.086 \\
\hline 0.169 & 0.098 & 0.194 & 0.119 & 0.199 & 0.148 & 0.211 & 0.144 & 0.258 & 0.155 & 0.179 & 0.084 \\
\hline 0.154 & 0.105 & 0.187 & 0.100 & 0.198 & 0.127 & 0.196 & 0.138 & 0.221 & 0.159 & 0.168 & 0.084 \\
\hline 0.172 & 0.110 & 0.161 & 0.115 & 0.180 & 0.135 & 0.203 & 0.156 & 0.260 & 0.167 & 0.174 & 0.077 \\
\hline 0.162 & 0.097 & 0.183 & 0.117 & 0.193 & 0.135 & 0.209 & 0.146 & 0.268 & 0.158 & 0.172 & 0.86 \\
\hline Mean : & & & & & & & & & & & \\
\hline 0.162 & 0.099 & 0.183 & 0.144 & 0.193 & 0.135 & 0.204 & 0.145 & 0.249 & 0.158 & 0.172 & 0.083 \\
\hline $\begin{array}{l}\text { SD } \pm: \\
0.008\end{array}$ & 0.009 & 0.012 & 0.008 & 0.008 & 0.008 & 0.006 & 0.007 & 0.019 & 0.006 & 0.005 & 0.003 \\
\hline
\end{tabular}

C - Control; T - Treatment

Fig 1. Regression line of log concentration of Acorus calamus partially putified extract vs. percent egg hatchability, mortality of larvae and puape of Culex quinquefasciatus.
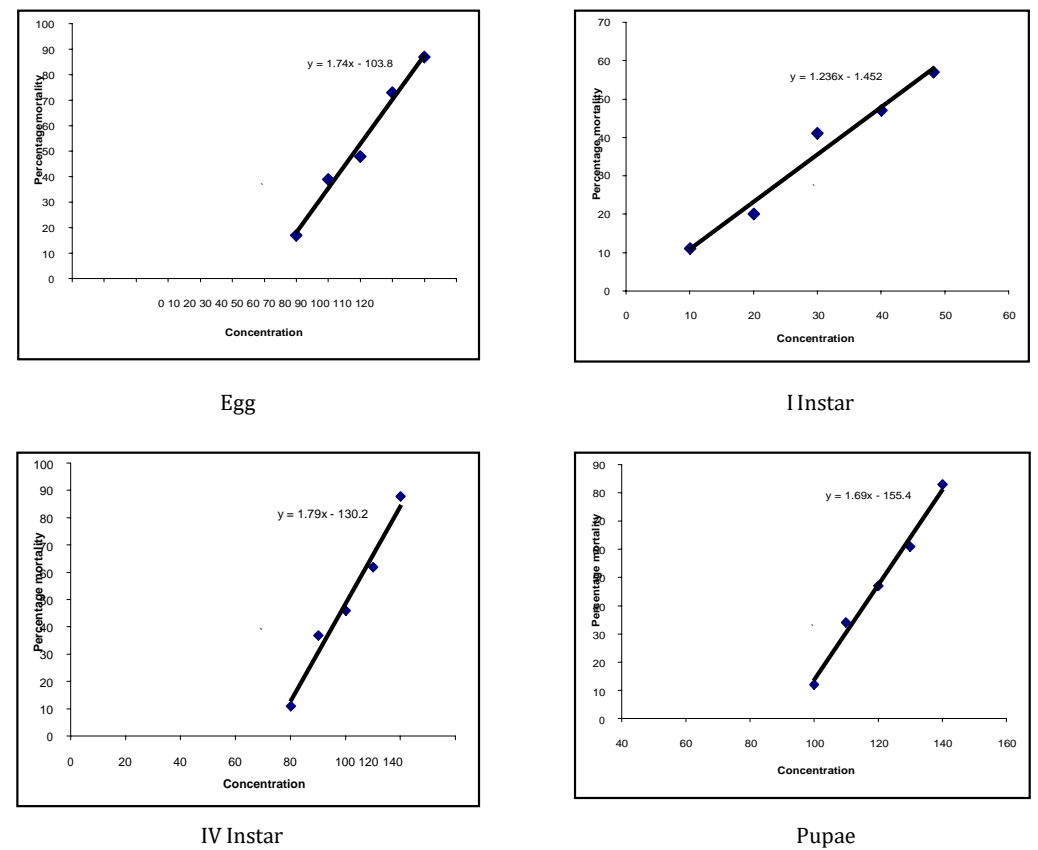